\title{
Multi-components exercise associated with dual task: Effects on physical functional performance and mobility of the older adults
}

\author{
Exercício multicomponente associado a dupla tarefa: efeitos no \\ desempenho físico funcional e mobilidade de idosos
}

Janine Carvalho Valentino Camargos', Milena Razuk', Kathisuellen R. Assis' ${ }^{1}$ Alex Tomé ${ }^{\prime}$, Natalia M. Rinaldi'.

1.Laboratory of Biomechanical Analysis of Human Movement, Center of Physical Education and Sports, Federal University of Espirito Santo, Brazil.

\begin{abstract}
Objective: The aim of this study was to verify the effect of dual task in a training protocol in the components of physical Functional Performance and mobility of older adults Methods: Thirty older adults (twenty-three female and seven males; 66.48 \pm 3.85 years) were distributed into three randomized groups: Multi-component physical activity group (MC), Dual Task Group (DT) and Control Group (CG). Participants were assessed before training and after 12 weeks of training with the following tests: Mini Mental State Examination, for evaluation of cognitive functions, AAHPERD test battery - American Alliance for Health, Physical Education, Recreation and Dance, for evaluation of five physical Functional Performance components, Timed Up and Go, for evaluation of functional mobility and The Baecke Questionnaire to assess the level of physical activity. Both MC and DT groups performed the same multi-components training protocol, however DT group performed simultaneously with a second cognitive task. Results: The groups that performed the training protocol improved some aspects of physical Functional Performance and mobility compared to the CG $(p<0.01)$. No difference was found between the DT and MC groups. Conclusion: Performing two simultaneous tasks in a training protocol does not seem to influence the functional capacity.
\end{abstract}

Key-words: Dual task training, Multi-components training, Physical functional performance.

\section{RESUMO}

Objetivo: O objetivo deste estudo foi verificar o efeito da dupla tarefa em um protocolo de treinamento nos componentes de Desempenho físico Funcional e mobilidade de idosos Métodos: Trinta idosos (vinte e três mulheres e sete homens; $66,48 \pm 3,85$ anos) foram distribuídos em três grupos randomizados: grupo de atividade física multicomponente (AM), grupo de tarefas duplas (DT) e grupo controle (GC). Os participantes foram avaliados antes do treinamento e após 12 semanas de treinamento com os seguintes testes: Mini Exame do Estado Mental, para avaliação das funções cognitivas, bateria de teste AAHPERD - American Alliance for Health, Physical Education, Recreation and Dance, para avaliação de cinco capacidades funcionais, Timed Up and Go, para avaliação da mobilidade funcional e o questionário de Baecke para avaliar o nível de atividade física. Os grupos AM e DT realizaram o mesmo protocolo 
de treinamento de múltiplos componentes, no entanto, o grupo DT realizou simultaneamente com uma segunda tarefa cognitiva. Resultados: Os grupos que realizaram o protocolo de treinamento melhoraram alguns aspectos do desempenho físico funcional e da mobilidade em comparação ao GC $(p<0,01)$. Não foi encontrada diferença entre os grupos DT e AM. Conclusão: A realização de duas tarefas simultâneas em um protocolo de treinamento não parece influenciar a capacidade funcional e a mobilidade..

Palavras-chave: Treinamento com dupla tarefa, Treinamento multi-componentes, Desempenho físico funcional.

\section{Introduction}

Aging is a natural process, which occurs changes characterized by physical and cognitive modifications, as well declines in all body system leading to structural and functional deterioration that may affect the level of physical activity, quality of life and physical functional performance $[1,2]$. Older adults population usually represents low levels in physical functional performance (PFP) due to deterioration of important body systems as the musculoskeletal, cardiorespiratory and nervous system $[3,4]$. PFP is defined as the efficiency of older people to accomplish safely to physical demands of daily life whether in simple or complex tasks $[5,6]$. This PFP is composed of six components: strength, agility/ dynamic balance, flexibility, coordination and aerobic endurance [6].

The PFP level can define the success or failure of the chosen activity to perform, as well directly connected with the autonomy [7]. Yet, a highly analyzed variable in combining with PFP and related to the autonomy of the older adults in daily life activities is mobility, which is characterized by more specific stimulations for agility and balance, from the combination of tasks. In the functional evaluation, the mobility established as an essential point because of the relations with physical functional performance [8].

Functional and structural losses are inevitable during the aging process, however scientific studies show that there is a possibility of improving or maintaining the functions of the body system through the practice of physical activity $[9,10]$. Physical activity is important to preserve the physical functional performance and the independence of older adults [11]. Studies report that the regular practice of physical activity produces benefits in cognitive and motor aspects, providing control of body composition, maintenance and increase of muscle strength, improvement of flexibility, and positive effects on the metabolism of older adults population, taking place as an important instrument of health promotion $[12,11]$.

According to the increase of population and necessity to offer better life conditions, exercise protocols has been created in order to understand the different effects of physical activity on physical Functional Performance or its components and what they bring as benefits [10]. For example, Pauli et al. [13] reported increased flexibility, shorter time for the coordination and agility test in a group of older adults who practiced different types of moderate intensity physical activity compared to a group of older adults who did not practice physical activity. Similar results were found by Scarabottolo [7] in a group of older individuals who combined of strength training with functional training for 12 weeks, with significant improvements in agility and strength. 
Some protocols used dual task exercises protocol (to perform two tasks simultaneously) to evaluate their effect on some aspects of physical Functional Performance. According to Hisayo Yokoyama [14], the training protocol associated with dual task (or-motor cognitive) is more beneficial than a single-task training, with improvement in extents of cognitive functions and muscle strength. The training protocol with dual task components showed to be effective in increasing the mobility of the older adults [15]. In addition, studies indicate that the training associating two tasks seems to benefit older adults mobility, presenting an increase in gait speed after the training [16,17]. Even though there are numerous studies that investigated the effects of training protocols for older adults, however, is not totally elucidated the effect of the dual task on the components of Physical Functional Performance and mobility of older adults, converting in to an important gap. In addition, many studies have performed the assessment of PFP by separating components and not evaluating all components $[7,14,15]$. Therefore, the aim of the present study was to verify the effect of dual task in a training protocol in all components of physical functional performance and mobility of older adults people.

\section{Methods}

\section{Participants}

Thirty older adults participated in this study (twenty-three female and seven males; $66.48 \pm 3.85$ years). The participants were distributed into three randomized groups: 1) Multi-component physical activity group (MC), 2) Dual Task Group (DT) and 3) Control Group (CG). As inclusion criteria, participants should show age between 60 and 80 years old. In addition, participants were able to walk without assistance. As exclusion criteria were: presence of neurological or musculoskeletal disorder that made it impossible to perform the training protocol and tests; attending to a systematic physical activity program (more than twice a week) or in the three-month period before to the start of the study; score < 24 points based on the Mini Mental State Examination (MMSE) scale [18]. Moreover, two consecutive faults or a total of three or more faults during the twelve weeks of training. The Institutional Ethics Committee of Federal University of Espírito Santo, Vitória, ES, Brazil approved the study protocol (71272817.0.0000.5542). In addition, all procedures were performed with the adequate understanding and written consent of all participants.

\section{Procedures}

All data collection and training protocols were made at the Fitness Station Gym in the city of Serra / ES. Participants were evaluated before the beginning of training (pre training) and after 12 weeks of training (post training). The following evaluation tools were used: 1) Anamnesis to characterize the profile of participants with information such as age, weight, height and current and past pathological history. 2) Mini Mental State Examination (MMSE), for evaluation of cognitive functions related to temporal / spatial orientation, memory, language, attention and calculation; The MMSE score ranges from 0 to 30 points [18]. 3) AAHPERD test battery - American Alliance for Health, Physical Education, Recreation and Dance, for evaluation of five Physical Functio- 
nal Performance components: Agility/ dynamic balance - time to complete two circuits involving the task stand up of a chair, walk around cones and return to the chair; Coordination - time to complete a task requiring a manipulation of twelve soda cans in a precise; Strength endurance- Number of elbow flexion repetitions associated with resistance in $30 \mathrm{~s}$; Flexibility- sit-and-reach test; Aerobic endurance- Time to complete an 880-yard walk [19]. 4) Timed Up and Go (TUG), for evaluation of functional mobility. The participants sat in a firm chair and were instructed to stand up from without using the arm rests and walk $3 \mathrm{~m}$ at their normal pace turn $180^{\circ}$ around a cone and return to the chair to sit down [20]. In order to increase the level of difficulty of the test it was performed associated with a second motor task (holding a tray with two cups) and associated with a second cognitive task (Countdown), named TUG motor and TUG cognitive, respectively. 5) The Baecke Questionnaire to assess the level of physical activity in three specific domains: household activities, sporting activities, and other physically active leisure. Scores are obtained through specific questions and the relationship between type, frequency and intensity of activity. The level of physical activity is proportional to the score [21].

\section{Training protocols}

Both groups performed the same training protocol that included different Physical Functional Performance components such as flexibility, agility, balance, strength, aerobic endurance and coordination. All exercises were performed in three sets of 10 to 12 repetitions. Each session lasted 50 minutes and was supervised by a qualified professional. The first and second week of exercises corresponded to the adaptive phase, which aimed at providing reeducation of functional tasks such as walking, sit and stand up. The sessions were divided into three parts: warm-up (5 minutes), with walk at their self-selected velocity; exercise training ( 35 minutes) and static stretching (10 minutes). The DT group performed the training protocol simultaneously with a second cognitive task. Cognitive exercises were based on MMSE, involving temporal and spatial orientation (approximate time, day of the week, month etc.), memory (short-term memory, which lasts for approximately 30 seconds), attention and calculation (perform mathematical calculations) evocation (recent memory with lasting minutes, weeks or months), language (reading, repetition and naming objects), repetition (auditory discrimination). The dependent variables calculated were: Agility/ dynamic balance(s), coordination(s), strength endurance (number of repetitions), aerobic endurance(s), flexibility $(\mathrm{cm})$ and TUG, TUG motor and TUG cognitive(s).

\section{Statistical analysis}

After data normality and homogeneity of variance assumptions were tested and fulfilled, one MANOVA-one way with repeated measures were employed (Group [Control group, Multi-component and Dual]) for the all variables of Physical Functional Performance and mobility. All dependent variables were calculated using Delta calculation $(\Delta=$ post Training - pre Training) to verify possible effects of the physical training protocol between the groups, with group factor (MC, DT, CG) for analysis of the following AAHPERD test variables: dynamic agility / balance, coordination, strength endurance, flexibility 
and aerobic endurance, and TUG: Functional Mobility (task execution time). Appropriate follow-up univariate analyses were performed, when applicable, with the overall significance level set at .05 . All analyses were performed using SPSS (SPSS for Windows 10.0). One-way analysis of variances (ANOVAs) were computed to compare age, anthropometric (height and body mass) and clinical characteristics (MMSE, and Baecke scores) between groups.

\section{Results}

\section{Sample characteristics}

The groups were similar in age ( $\mathrm{GC}=66.1$ years $\mid \mathrm{MC}=67$ years $\mid \mathrm{DT}=65.8$ years), cognition and level of physical (Table I). The volunteers obtained total frequency in the physical exercise programs.

Table I - Mean and standard deviation (in parenthesis) of age and clinical characteristics of the control (CG), Multicomponent (MC) and Dual task (DT) groups.

\begin{tabular}{|l|l|l|l|l|}
\hline Characteristics & CG & MC & DT & P-value \\
\hline Age (years) & $66.1(3.4)$ & $67(4.29)$ & $65.8(4.1)$ & 0.7 \\
Baecke questionnaire (points) & $1.58(0.51)$ & $1.45(0.59)$ & $1.69(0.38)$ & 0.6 \\
Mini Mental State Examination (points) & $24(1.56)$ & $24.7(1.33)$ & $24.2(1.47)$ & 0.55 \\
\hline
\end{tabular}

Physical functional performance variables

MANOVA showed a significant effect of group (Wilks' Lambda $=0.232$, $\mathrm{F} 10.46=4.955, \mathrm{p}<0.01)$. ANOVA showed a significant effect of agility/ dynamic balance $(\mathrm{F} 2.27=4.373, \mathrm{p}=0.023)$, coordination $(\mathrm{F} 2.27=10.572, \mathrm{p}<0.001)$, flexibility (F2.27 $=9.936, \mathrm{p}=0.001)$ and aerobic endurance $(\mathrm{F} 2.27=3.9, \mathrm{p}=0.03)$, but no effect of strength endurance $(\mathrm{F} 2.27=2.787, \mathrm{p}=0.079)$. Post hoc tests showed that the MC and DT groups presented higher flexibility $(3.0 \mathrm{~cm} / 3.7 \mathrm{~cm}$ respectively) and less time in coordination test $(-9.9 \mathrm{~s} /-1.3 \mathrm{~s}$ respectively) compared to CG (0.10 s / $0.4 \mathrm{~s}$ respectively). Furthermore, post hoc tests showed that the DT group presented less time for the agility/ dynamic balance test than CG $(-2.79 \mathrm{~s} /-2.1 \mathrm{~s}$ respectively), and $\mathrm{MC}$ showed less time for the aerobic endurance test than $\mathrm{CG}(-1.376 \mathrm{~s} /-6.2 \mathrm{~s}$ respectively) (Figure 1 ).

\section{Functional mobility variables}

ANOVA showed a significant effect of mobility for the group (Wilks' Lambda $=0,519, F 6,50=3.234, p=0.009$ ). Post hoc tests revealed that MC and DT groups showed lower time to perform the test TUG $(-7600 /-7900)$ compared to the CG $(-2600)(\mathrm{p}=0.033 / \mathrm{p}=0.023$ respectively). Thus, post hoc tests showed that the DT group had lower time in the TUG M (-6000) test than compared to the CG $(0.1000)(\mathrm{p}=0.025)$ (Figure 2). 

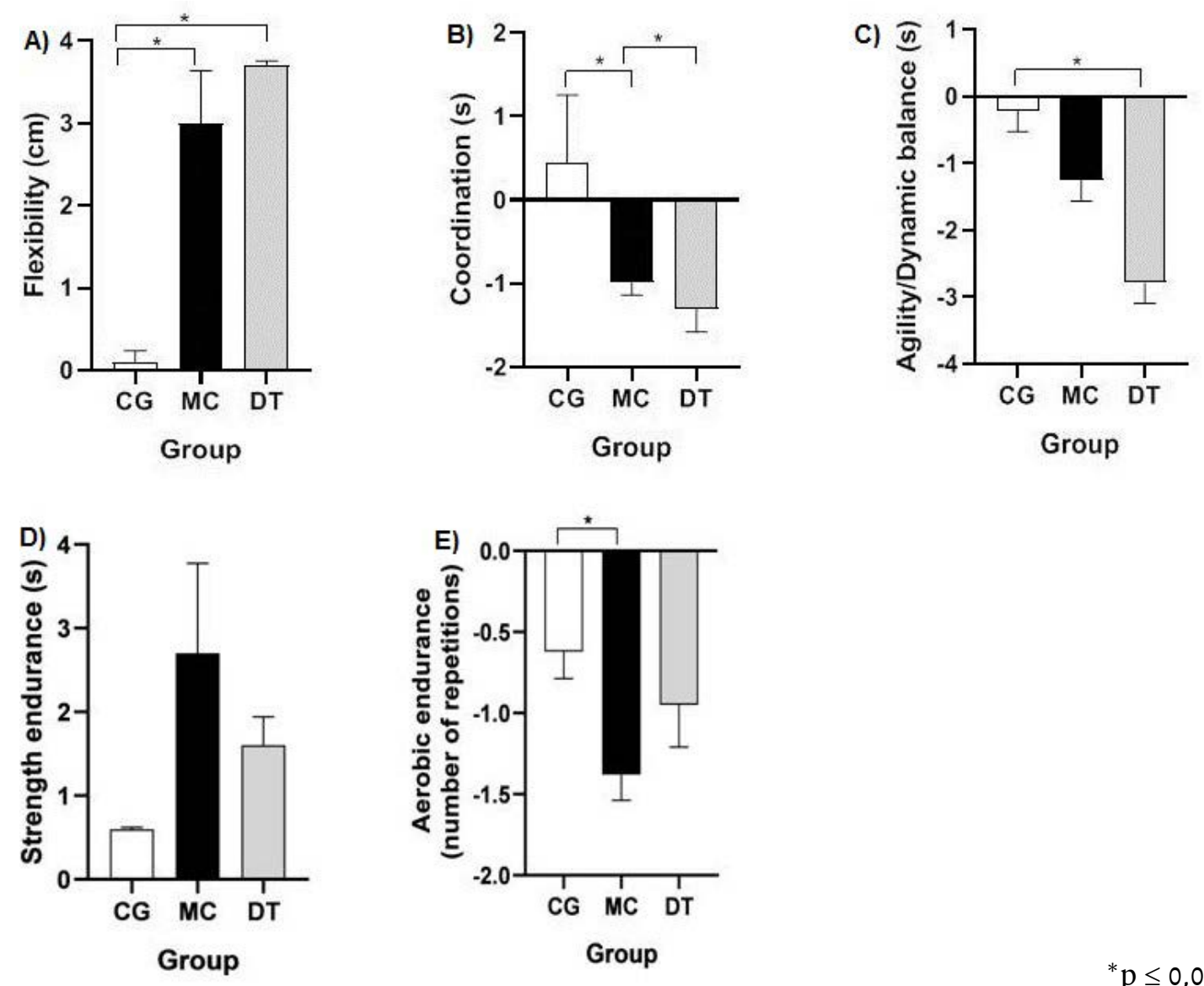

${ }^{*} \mathrm{p} \leq 0,05$

Figure 1 - Mean and standard deviation of the control (CG), Multicomponent (MC) and Dual task (DT) groups in the following Physical Functional Performance variables: flexibility (A), coordination (B), agility/ dynamic balance (C), strength endurance (D), and aerobic enduran$\mathrm{ce}(\mathrm{E})$.

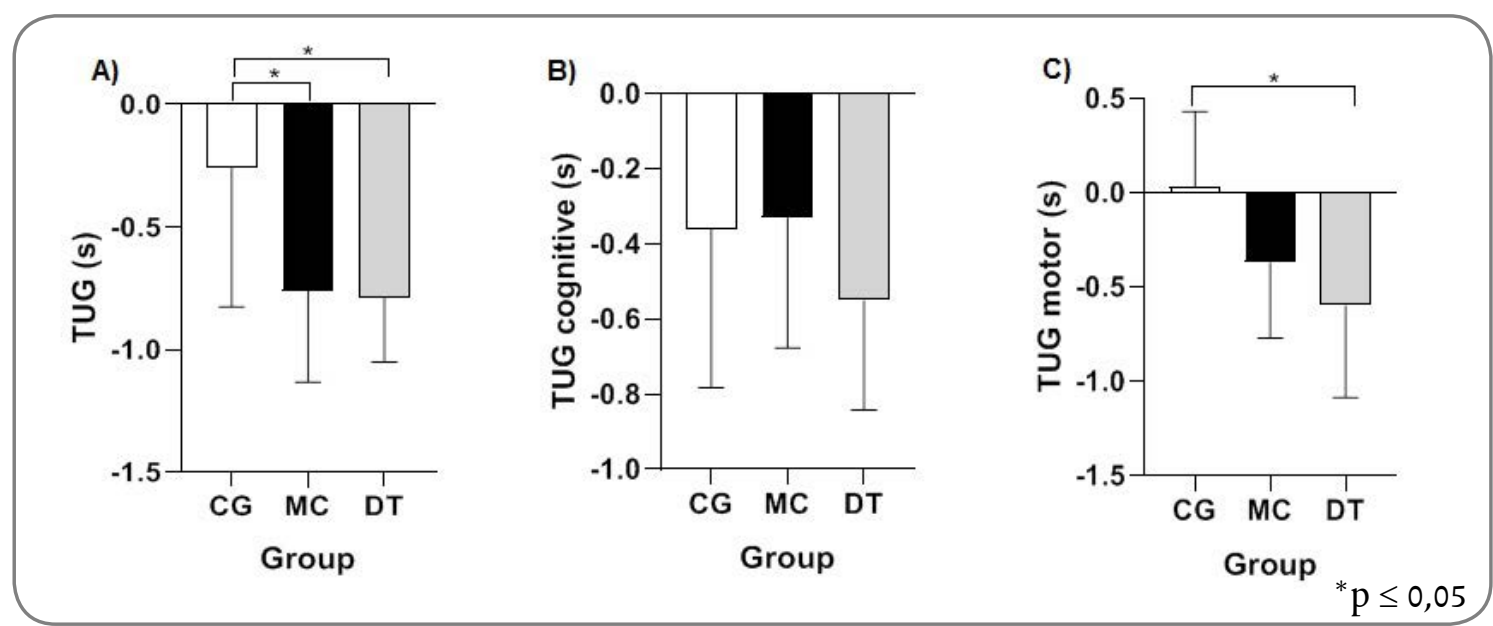

Figure 2 - Mean and standard deviation of the control (CG), Multicomponent (MC) and Dual task (DT) groups in the mobility variable, TUG (A), TUG cognitive (B) and TUG motor (C).

\section{Discussion}

The aim of the present study was to verify the effect of dual task in a training protocol in all components of Physical Functional Performance and mobility of older adults. Overall, the dual task had no effect on the variables of Physical Functional Performance, because both groups showed performed better in some aspects of CF and mobility. This could be explained by the fact 
that physical activity generally promotes positive impacts in functional aspects, such as increased aerobic capacity, preservation of muscle mass, improved functionality and autonomy in activities $[3,7,12]$.

In addition, performing two simultaneous tasks increases the demand for central nervous system processing when compared to a single task, and the more attention given to performing a task, the higher the level of interference in the secondary task [22,23]. This interference can be improved by training, increasing performance during the dual task [22]. Therefore, the addition of the dual task in the training protocol may not have influenced the variables of the Physical Functional Performance due to the low level of difficulty and complexity of the secondary task, not being challenged enough to generate impact on the $\mathrm{CF}$ variables.

In relation to $\mathrm{CF}$, both groups ( $\mathrm{MC}$ and $\mathrm{DT}$ ) presented differences for the variables of flexibility and coordination, corroborating with the results found by Pauli et al. [13], where the coordination and flexibility effects of older adults people who practiced different types of physical activity at moderate intensity were evaluated, using the AAHPERD scale as an analysis tool. In the present study, the only variable that did not present an effect was muscle strength, which can be explained by the fact that the activities were not directed to the systematic training of muscle strengthening. Carvalho et al. [24] compared the muscular strength of the older adults before and after 24 weeks of two types of training (Multi-components and resistance). No differences were found for muscle strength in the multicomponent physical activity group. The study concludes that multi-component training does not appear to influence muscle strength; however, resistance training in the multi-component exercise protocol improves muscle strength in the older adults.

In addition, the present study the Multi-component physical activity group presented better performance in aerobic endurance, which can be explained by the fact that they are only dedicating themselves to single task. In addition, exercise protocols of the present study favor the impact of this variable, due to the number of aerobic exercise time in the training protocol The magnitude of aerobic endurance improvement is determined by the intensity and frequency of exercise [25].

In relation to mobility, Menezes et al. [26] found an improved mobility by decreasing the time to perform the TUG test of the older adults after four months of intervention with multi-component protocol; Lorca and Lepe [27] also found that the older adults perform the fastest TUG test after a year of muscle strength training, flexibility and balance. Also, studies report that dual-task training leads to better performance in the mobility of the older adults, as shorter time to perform the TUG test $[14,15]$ and increased gait speed $[16,17]$. In the present study, similar results were found, because both training protocols improved performance during the TUG test, with shorter test time after training. This result was precipitated, since the practice of physical activity being maintained or improving the mobility of the older adults [28]. In the mobility test associated with a second motor task, the DT group presented shorter test time and better performance than the CG. Hisayo Yokoyama [14] evaluated the effect of dual-task training on executive functions and concluded that cognitive-motor dual-task training was more beneficial than single-task training in improving broader domains of cognitive functions in older people. The improvement of executive function may be a possible explanation for the better per- 
formance of the DT group in the dual task mobility test when compared to the CG.

The second task proposed in the protocol of this study may not have been complex enough to generate an effect on Physical Functional Performance. The aging process causes deterioration in the central nervous system, however, these changes are limited to more complex processes, such as executive function, which refers to the ability to plan strategies [29] so maybe the difference between the protocols was not found because the second task was not complex enough. A possible limitation of the study was the low complexity of the second task in the training protocol, and the training time. Thus, for future studies we suggest a greater complexity of the second task and an increase in total training time.

\section{Conclusion}

Both training protocols improve the Physical Functional Performance of the older adults, regardless of the dual task in training

\section{References}

1. Macena WG, Hermano LO, Costa TC. Alterações fisiológicas decorrentes do envelhecimento. Rev Mosaicum 2018;27:223-36.

2. Nascimento CM, Ingles M, Salvador-Pascual A, Cominetti MR, Gomez CMC, Viña J. Sarcopenia, frailty and their prevention by exercise. Free Radic Biol Med 2018;132:42-9. https://doi.org/ 10.1016/j.freeradbiomed.2018.08.035

3. Tomás MT, Galán-Mercant A, Carnero EA, Fernandes B. Functional capacity and levels of physical activity in aging: A 3-year follow-up. Front Med 2017;9(4):244. https://doi.org/ 10.3389/ fmed.2017.00244

4. Carmona JJ, Michan S. Biology of healthy aging and longevity. Rev Invest Clin 2016;68(1):716.

5. Berlezi EM, Farias AM, Dallazen F, Oliveira KR, Pillatt AP, Fortes CK. Analysis of the functional capacity of elderly residents of communities with a rapid population aging rate. Rev Bras Geriatr Gerontol 2016;19(4):643-52. https://doi.org/10.1590/1809-98232016019.150156

6. Clark BA. Tests for fitness in older adults: AAHPERD Fitness Task Force. Joperd 1989;60(3):6671. https://doi.org/10.1080/07303084.1989.10603976

7. Scarabottolo CC, Garcia JJR, Gobbo LA, Alves MJ, Ferreira AD, Zanuto EAC et al. Influence of physical exercise on the functional capacity in institutionalized elderly. Rev Bras Med Esporte 2017;23(3):200-3. https://doi.org/10.1590/1517-869220172303150175

8. Lin SI, Lee HC, Chang KC, Yang YC, Tsauo JY. Functional mobility and its contributing factors for older adults in different cities in Taiwan. J Formos Med Assoc 2017;116(2):72-9. https://doi. org/10.1016/j.jfma.2016.01.011

9. Ferreira CB, Teixeira PDS, Alves dos Santos G, et al. Effects of a 12-week exercise training program on physical function in institutionalized frail elderly. J Aging Res 2018;2018:1-9. https:// doi.org/10.1155/2018/7218102

10. Pereira AMG, Paulo TRS, Santos SFS. Efeito do exercício físico na capacidade funcional e atividade da vida diária em idosos: revisão sistemática. ACTA Brasileira do Movimento Humano 2015;5(2):79-95.

11. Nelson ME, Rejeski WJ, Blair SN, Duncan PW, Juiz JO, Rei AC, et al. Physical activity and public health in older adults: recommendation from the American College of Sports Medicine and the American Heart Association. Med Sci Sports Exerc 2007;39(8):1435-45. https://doi. org/10.1249/mss.0b013e3180616aa2

12. Granacher U, Hortobágyi T. Exercise to improve mobility in healthy aging. Sports Med 
2015;45:1625-26. https://doi.org/10.1007/s40279-015-0405-9

13. Pauli J, Souza LS, Zago AS, Gobbi S. Influência de 12 anos de prática de atividade física regular em programa supervisionado para idosos. Rev Bras Cineantropom Desempenho Hum 2009;11(3):255-60. https://doi.org/10.5007/1980-0037.2009v11n3p255

14. Yokoyama H, Okazaki K, Imai D, Yamashina Y, Takeda R, Naghavi N et al. The effect of cognitive-motor dual-task training on cognitive function and plasma amyloid beta peptide $42 / 40$ ratio in healthy Older adults persons: a randomized controlled trial. BMC Geriatr 2015;15(60):210. https://doi.org/10.1186/s12877-015-0058-4

15. Brustio PR, Rabaglietti E, Formica S , Liubicich ME. Dual-task training in older adults: The effect of additional motor tasks on mobility performance. Arch Gerontol Geriatr 2018;75:119-24. https://doi.org/10.1016/j.archger.2017.12.003

16. Gregory MA, Gill DP, Zou G, Liu-Ambrose T, Shigematsu R, Fitzgerald C, et al. Group-based exercise combined with dual-task training improves gait but not vascular health in active older adults without dementia. Arch Gerontol Geriatr 2016;63:18-27. https://doi.org/10.1016/j.archger.2015.11.008

17. Silsupadol P, Shumway-Cook A, Lugade V, Van DP , Chou LS , Mayr U. Effects of single-task versus dual-task training on balance performance in older adults: a double-blind, randomized controlled trial. Arch Phys Med Rehabil 2009;90(3):381-7. https://doi.org/10.1016/j. apmr.2008.09.559

18. Melo DM, Barbosa AJG. O uso do Mini-Exame do Estado Mental em pesquisas com idosos no Brasil: uma revisão sistemática. Ciênc Saúde Coletiva 2015;20(12):3865-76. https://doi. org/10.1590/1413-812320152012.06032015

19. Benedetti TRB, Mazo GZ, Goncalves, LHT. Bateria de testes da AAHPERD: adaptação para os institucionalizados. Rev Bras Cineantropom Desempenho Hum 2014;16(1):1-14. https://doi. org/10.5007/1980-0037.2014v16n1p1

20. Podsiadlo D, Richardson S. The timed "Up \& Go": a test of basic functional mobility for frail older adults' persons. J Am Geriatr Soc 1991;39(2):142-8. https://doi.org/10.1111/j.1532-5415.1991. tb01616.x

21. Voorrips LE , Ravelli AC, Dongelmans PC , Deurenberg P, Van SWA. A physical activity questionnaire for the elderly. Med Sci Sports Exerc 1991;23(8):974-9.

22. Matthews A, Garry MI, Martin F, Summers J. Neural correlates of performance trade-offs and dual-task interference in bimanual coordination: an ERP investigation. Neurosci Lett 2006;400(1):172-6. https://doi.org/10.1016/j.neulet.2006.02.043

23. Ghai S, Ghai I, Effenberg AO. Effects of dual tasks and dual-task training on postural stability: a systematic review and meta-analysis. Clin Interv Aging 2017;12:557-577. https://doi. org/10.2147/CIA.S125201

24. Carvalho J, Marques E, Soares JM , Mota J . Isokinetic strength benefits after 24 weeks of multicomponent exercise training and combined exercise training in older adults. Aging Clin Exp Res 2010;229(1):63-9. https://doi.org/10.1007/BF03324817

25. Varela S, Ayan C , Cancela JM, Martin V . Effects of two different intensities of aerobic exercise on elderly people with mild cognitive impairment: a randomized pilot study. Clin Rehabil 2012;26(5):442-50. https://doi.org/10.1177/0269215511425835

26. Menezes AV, Aguiar AS, Alves EF, Quadros LB, Bezerra PP. Efetividade de uma intervenção fisioterapêutica cognitivo-motora em idosos institucionalizados com comprometimento cognitivo leve e demência leve. Ciênc Saúde Colet 2016;21(11):3467-2016. https://doi.org/10.1590/1413812320152111.17892015.

27. Lorca NM, Lepe LM, Diaz NVP, Araya OE. Efectos de un programa de ejercicios para evaluar las capacidades funcionales y el balance de un grupo de adultos mayores independientes sedentarios que viven en la comunidad. Salud Uninorte. 2011;27(2):185-97.

28. Wang RY, Wang YL, Cheng FY, Chao YH, Chen CL, Yang YR. Effects of combined exercise on gait variability in community-dwelling older adults. Effects of combined exercise on gait variability in community-dwelling older adults. Age Dordr 2015;37(3):40. https://doi.org/10.1007/ s11357-015-9780-2

29. Poranen CT, Von BMB, Rantakokko M, Portegijs E, Eronen J, Kauppinen M, et al. Executive function and life-space mobility in old age. Aging Clin Exp Res 2018;30(2):145-151. https://doi. org/ $10.1007 /$ s40520-017-0762-3 